Página inicial: 497 - Página Final: 512

Tipo de artículo: Investigación

\title{
La memoria del conflicto armado en Bucaramanga: análisis de una experiencia investigativa desde las voces de las víctimas ${ }^{i}$
}

\author{
Memoir of Armed Conflict in Bucaramanga: An Analysis of Research Experience from \\ Victims' Voices
}

Recibido: abril de $2017 \quad$ Revisado: mayo de $2017 \quad$ Aceptado:junio de 2017

${ }^{1}$ Historiadora de la

Universidad Industrial de

Santander (UIS).

Bucaramanga. (Colombia). ORCID

http://orcid.org/0000-0001$\underline{8760-5384}$

2 Historiador y Archivista de la Universidad Industrial de Santander (UIS).

Bucaramanga.

(Colombia).Contacto:

diegoescamillag12@yahoo.co

m.ar.

ORCID:

http://orcid.org/0000-0002$\underline{8866-6629}$
Por: Lahdy Diana del Pilar Novoa Sanmiguel ${ }^{1} \&$ Diego Andrés

Escamilla Márquez ${ }^{2}$

\section{Resumen}

La relación del conflicto armado interno colombiano y el Área Metropolitana de Bucaramanga (Colombia), dentro de los estudios históricos de esta ciudad, es todavía una tarea pendiente. En este orden, es necesario complejizar los abordajes actuales en los estudios respecto a identidades, referentes, marcos y expresiones de la memoria en contextos de prolongado conflicto armado como es el caso de Colombia. Así mismo, es importante señalar nuevas posibilidades de investigación en lo referente a las relaciones de dicho conflicto armado persistente y la configuración de dichos referentes, marcos y expresiones de la memoria

Palabras clave. Memoria histórica; historial oral; conflicto armado; historia contemporánea; Colombia; víctimas.

\begin{abstract}
The relationship of the Colombian internal armed conflict and the Metropolitan Area of Bucaramanga, Colombia, within the historical studies of this city, is still a pending task. In this order, it is necessary that current studies regarding identities, relating approaches, frameworks, and expressions of memory, in contexts of prolonged armed conflict as in the case of Colombia, can be made more complex. Likewise, it is important to point out new possibilities of research regarding the relations of the persistent armed conflict and the configuration of related sayings, frames of reference, and expressions of memory.
\end{abstract}

Key words: Historical Memoir; Oral History; Armed Conflict; Contemporary History; Colombia; Victims. 


\section{Introducción}

Entre los años 2013-2016, el grupo de investigación Historia Archivística y Redes de Investigación (HARED) de la Universidad Industrial de Santander (UIS), logró que Colciencias aprobara la financiación del proyecto Puesta en marcha de un archivo oral de memoria en el Área Metropolitana de Bucaramanga. Verdades no contadas: el conflicto armado colombiano desde la memoria de las víctimas (Escamilla Márquez, 2013), que buscó ampliar los alcances de un proyecto anterior titulado Estudio de trayectorias de vida de personas en situación de desplazamiento forzado interrelacionadas en el barrio Café Madrid del municipio de Bucaramanga (Suárez Pinzón, Ardila , Baéz, \& Rueda, 2010), también financiado por Colciencias entre los años 2012-2013. (AMOVI, 2010)

Ambos proyectos, ejecutados por investigadores de HARED, pretendieron construir memoria del conflicto colombiano a partir de las voces de las víctimas, por lo que se recurrió, dentro de sus enfoques y metodologías, a los planteamientos venidos de la historia oral, la historia desde abajo y la historia del tiempo presente. En el segundo de estos proyectos se adicionó, de manera importante, la cuestión archivística, considerando los problemas y las particularidades que revestían la organización, conservación y acceso de la documentación producida en este tipo de investigaciones, especialmente la documentación oral aportada por las víctimas. De este modo, durante los casi tres años que duró este segundo proyecto, se dio la creación del Archivo Oral de Memoria de las Víctimas en la UIS, AMOVI-UIS (AMOVI, 2010), que se ha venido posicionando en los ámbitos local, regional y nacional, como un referente de investigación en lo concerniente al conflicto armado interno colombiano, Derechos Humanos, memoria histórica y víctimas.

Este segundo proyecto, además, se trazó como objetivos la elaboración de 30 trayectorias de vida de víctimas asentadas en el Área Metropolitana de Bucaramanga y un informe de categorías de las entrevistas hechas a estas 30 personas. Las categorías conflicto armado interno, memoria y redes sociales, organizaron las inquietudes a indagar dentro de las entrevistas y configuraron la matriz central a partir de la cual se elaboró el mentado informe categorial. El presente artículo hace parte del análisis que, en relación con la categoría memoria, se hizo a las entrevistas de estas 30 personas víctimas. No nos remitiremos en esta ocasión a los aspectos metodológicos seguidos en la investigación, si bien los mismos pueden ser consultados y analizados en un trabajo que ya ha sido publicado (Escamilla Márquez \& Novoa Sanmiguel, 2017).

\section{Memoria histórica razonada: un punto de partida (y de llegada)}

La propuesta de una memoria bistórica razonada fue formulada por los investigadores proponentes de la primera investigación ya citada. Desde aquella ocasión, dicha memoria se ha definido como un producto de valoración crítico-analítica que busca que, víctimas y sociedad en general, superen el pasado como mero hecho doloroso y lo pongan a disposición de la construcción de un futuro mejor desde el presente (Suárez Pinzón, y otros, 2010, pág. 18).

En un primer momento esta propuesta reflexionó sobre la necesidad de incluir víctimas, puesto que, en aquellos años (2009-2010), la construcción oficial de la memoria del conflicto armado interno colombiano se basaba, casi de manera exclusiva, en los testimonios de los victimarios adscritos a la Ley de Justicia y Paz de 2005. Esta inclusión significaba el preámbulo a reivindicaciones sociales y políticas de mayor envergadura para las víctimas, pero también la posibilidad de otro tipo de historia 
para la sociedad colombiana, una historia crítica de la historia estatal, surgida desde las voces de los sectores más vulnerados. En este sentido, la memoria histórica raz̧onada ha pretendido desde sus inicios concatenar los fines propios del conocimiento histórico, con las reclamaciones de los movimientos sociales, para este caso puntual, las reclamaciones de las víctimas del conflicto armado interno.

No obstante, con la promulgación de la Ley 1448 de 2011, la inclusión pareció ser un problema resuelto, pues con dicha Ley se obligó a las instituciones estatales encargadas de la gestión del recuerdo sobre el conflicto, a incorporar de manera primordial la versión de las víctimas y fomentar su participación. Esta formalidad se ha extendido no solo a las instituciones oficiales sino también a otras entidades del orden nacional e internacional (medios de comunicación, establecimientos educativos, agencias de cooperación, etc.), a tal punto que hoy todos los organismos consideran esencial incluir a las víctimas dentro de los programas de construcción de memoria histórica. Ante este nuevo escenario, las dificultades ya no estriban en la inclusión, sino en la instrumentalización que se ha hecho de dicha inclusión, es decir, el abordaje, tratamiento y análisis que dichas entidades les dan a los testimonios de las víctimas.

Desde la investigación que hemos adelantado se han advertido dos aspectos fundamentales resultantes de esta instrumentalización: por un lado, la ponderación del humanitarismo, y por el otro, la búsqueda pragmática de la concordia nacional. Esto no sería reprochable, sino fuera porque esta mirada humanitarista y "conciliadora" la han sobreexplotado con miras a ocultar e impedir un conocimiento más profundo del conflicto, conocimiento que permitiría a las víctimas y la sociedad en su conjunto una mayor comprensión de las causas sociales y políticas del mismo, punto de partida obligatorio sin en el cual cualquier pretensión de una paz estable y duradera será solo una ilusión.

Teniendo en cuenta esta nueva situación, el concepto de memoria histórica razonada supone hoy, además de seguir siendo incluyente con las víctimas, trabajar con más esmero en los ejercicios de conversación y deliberación entre éstas y los investigadores, con el fin de que unos y otros, a partir de sus experiencias y conocimientos previos, se asuman como sujetos activos de la historia, es decir, no solo como memorialistas del pasado, sino también como agentes de cambio, pues el fondo de esta propuesta, como lo hemos señalado en otros trabajos, es una memoria que comprenda el pasado para que víctimas y sociedad en general puedan contribuir a la resolución de las problemáticas sociales vigentes (Escamilla Márquez \& Novoa Sanmiguel, 2016).

\section{Rutas de enunciación de la memoria del conflicto en Colombia}

La pretensión de una memoria histórica razonada no es la única intención que existe en el país con relación a los trabajos de memoria. Colombia ha experimentado, en lo que va del siglo XXI, un auge en las apuestas de memoria sin precedente, apuestas a las que ha sido muy difícil seguirles la pista en toda su versatilidad. Un intento de comprender esta pluralidad lo ha elaborado Oscar Fernando Acevedo Arango (2012) en su libro Geografías de la memoria: Posiciones de las víctimas en Colombia en el periodo de justicia transicional (2005-2010). Este autor ha perfilado una taxonomía de las iniciativas de memoria realizadas en Colombia que, a nuestro parecer, se aproxima bastante bien a la dinámica que presenta el fenómeno en la actualidad. Acevedo señala que en Colombia se han venido definiendo cuatro rutas de enunciación con relación a la memoria, las cuales él propone denominar de la siguiente manera: memorias oficiales, memorias agonistas, memorias sub/alternas y memorias reservadas. 
Las primeras se erigen desde las élites y el sector público del gobierno; se apoyan en discursos y técnicas de organismos internacionales, encuentran eco en los principales medios de comunicación y están determinadas generalmente por los objetivos judiciales del Estado. Las memorias agonistas, por otro lado, son aquellas que se oponen, en un grado mayor, a las memorias oficiales; pugnan por posicionar los recuerdos de los excluidos en la historia y la memoria nacional; cuentan con cierta capacidad mediática y le disputan a las memorias gubernativas el poder público central, es decir, "los privilegios de estar en una posición dominante dentro de la historia” (Acevedo Arango, 2012, pág. 59).

En cuanto a las memorias sub/alternas, el autor las define como aquellas que no hacen parte ni de los proyectos gubernativos ni agonistas, es decir, están "por fuera de la disputa por el poder dominante: son comunitarias, artísticas y religiosas, visibles en las prácticas de localidades periféricas, en sujetos colectivos distanciados de las redes de la sociedad política organizada" (Acevedo Arango, 2012, pág. 68-69). Estas memorias de y para las víctimas no buscan politizar el pasado sino dignificarlo, en otras palabras, convertirlo por medio de la conmemoración y la reconciliación en un "patrimonio intangible antes que un campo de luchas" (Acevedo Arango, 2012, pág. 96). Las memorias reservadas, por último, son aquellas que se encuentran silenciadas o en estado de latencia. Su todavia-no-aparición puede deberse o a un exceso de miedo (memorias aterrorizadas) o a un exceso de vergüenza (memorias vergonzantes), sin embargo, sean lo que sean, estas memorias tienen el potencial de cambiar, según Acevedo, lo que hasta ahora se conoce de la memoria (Acevedo Arango, 2012, págs. 96-112).

Estas rutas no son para el autor una demarcación estática, pues es evidente que entre las diferentes iniciativas puede haber un tránsito "ascendente", es decir, de memorias reservadas pasar a memorias sub/alternas y de ahí a memorias agonistas o memorias oficiales, e incluso, pueden coexistir en distintas versiones de enunciación.

Lo concerniente a la memoria en nuestra investigación, se enmarca dentro de los tránsitos o dinamismos de este último aspecto. Primeramente, porque siendo esta investigación financiada por una entidad estatal (Colciencias), la apuesta ha sido agonista, o por lo menos nació bajo la premisa de ser una crítica a las versiones hegemónicas que para aquel momento (2010) estaban circulando. No obstante, el trabajo comunitario, local y regional que se ha venido haciendo durante estos años, ha privilegiado, dentro de la investigación, también una memoria de tipo sub/alterna, como la describe Acevedo, pues ha consistido principalmente en visibilizar, reconocer y reivindicar a las víctimas asentadas en el Área Metropolitana de Bucaramanga y sus alrededores. Además, aunque desde el inicio hemos procurado una memoria histórica razonada, somos conscientes que ésta no es la pretensión de todos los participantes de la investigación y que objetivos de menor envergadura, no por ello menos importantes, también deben ser tenidos en cuenta en lo que respecta a la gestión del pasado violento de Colombia.

Otra particularidad de esta investigación estriba en el abordaje de la memoria de las víctimas, no solo en relación con los hechos victimizantes en sí, sino con toda la experiencia vital o trayectorias de vida de las mismas. En otras palabras, se trata de conocer cómo una víctima construye memoria del conflicto armado interno colombiano desde una visión que sobrepasa la coyuntura de los hechos victimizantes y se aproxima a una perspectiva mucho más interconectada con las estructuras históricas de la sociedad colombiana. De este modo, la memoria que construimos desde las víctimas en esta investigación, busca que los recuerdos que ellas tienen de la infancia, la juventud, la adultez, el contexto social, las geografías y cualquier otra información concerniente al antes, durante y después de la 
victimización, les ayude a ellas, a nosotros y a toda la sociedad colombiana en general, a comprender mucho más profundamente las causas, las dinámicas y las consecuencias del conflicto armado interno.

Hechas estas consideraciones, la presente investigación encontró cuatro (4) tópicos vinculados a la memoria, mediante los cuales las treinta (30) víctimas participantes, asentadas en el Área Metropolitana de Bucaramanga y sus alrededores, relacionaron sus experiencias de vida hasta el momento de las entrevistas (años 2013-2016). Como era de esperarse y dados los objetivos planteados en la investigación, se buscó profundizar en los hechos relativos al conflicto, que, por ser episodios de violencia, constituyeron significativas "bisagras" en la existencia vital de los entrevistados. Estos cuatro (4) tópicos los denominamos de la siguiente manera: identidades, referentes de memoria, marcos sociales de memoria y expresiones de memoria.

\section{Identidades, referentes, marcos y expresiones: una aproximación de cómo las víctimas se relacionan con la memoria}

\section{Identidades}

Murguia, a propósito de la relación entre memoria y procesos identitarios, afirma que la importancia de ésta en dichos procesos radica en sus distintas formas de expresar la vivencia en el tiempo y de permanecer en él (2011, pág. 21). Estas construcciones del tiempo transcurrido configuran la identidad, según Ricoeur, en dos aspectos: ipse e idem, es decir, en la definición que de sí mismo hace el sujeto al pronunciarse a manera de promesa sobre su propio carácter, y, en las definiciones que se le irán suscitando en su devenir cambiante (2000, págs. 110-111). Esta construcción dinámica de las identidades ha sido expresada por los entrevistados* en por lo menos tres (3) aspectos: los referentes con que se autodefinen, sus proyectos de vida y el contexto socioeconómico.

Los mencionados referentes son aquellos elementos sociales y subjetivos mediante los cuales las víctimas afirman o construyen la imagen de sí mismas. Los elementos sociales pueden estar dados por la religión en la que los entrevistados nacieron o a la que posteriormente se convirtieron (judía, católica o pentecostal) (Entrevista No 17, 30 de abril de 2014) (Entrevista No 30, 23 de octubre de 2015) (Entrevista No 2, 02 de diciembre de 2013), el lugar de procedencia de cada uno de ellos o el de sus padres (Guajira, Antioquia, García Rovira, etc.) (Entrevista No 17, 30 de abril de 2014) (Entrevista No 6, 23 de octubre de 2015) (Entrevista No 24, 04 de septiembre de 2014), el barrio donde crecieron o donde actualmente residen (Entrevista No 19, 14 de mayo de 2014) (Entrevista No 29, 13 de julio de 2015), la cultura étnica en la que se asumen (Entrevista No 17, 30 de abril de 2014), sus familias (específicamente los padres) (Entrevista No 2, 02 de diciembre de 2013) (Entrevista No 17, 30 de abril de 2014) (Entrevista No 18, 02 de mayo de 2014) (Entrevista No 20, 27 de mayo de 2014), la orfandad (Entrevista No 6, 23 de octubre de 2015), las actividades económicas -campesino, sastre, vendedor, músico, docente, gestor cultural, etc.- (Entrevista No 18, 02 de mayo de 2014) (Entrevista No 24, 04 de septiembre de 2014) (Entrevista No 29, 13 de julio de 2015), (Entrevista No 18, 02 de mayo de 2014) (Entrevista No 24, 04 de septiembre de 2014) (Entrevista No 29, 13 de julio de 2015), (Entrevista No 10, 20 de enero de 2016), (Entrevista No 6, 23 de octubre de 2015), (Entrevista No 5, 21 de diciembre de 2013) los apodos que sus entornos más cercanos les adjudicaron (Entrevista No 6, 23 de octubre de 2015) y/o el partido político al que pertenecieron (Entrevista No 28, 08 de julio de 2015). 
Estos elementos no son estáticos. Algunos entrevistados, por ejemplo, que eran campesinos antes de ser desplazados, solo conservan las representaciones o los valores de la cultura campesina, pues una vez que arribaron a la ciudad, no pudieron volver a ejercer esa labor. Hoy, algunos de estos campesinos se desempeñan en la jardinería, por lo que la nueva identidad en construcción es la de "jardineros". Otros, también campesinos, se han dedicado a ser líderes comunitarios o de asociaciones de víctimas, y se autodenominan así mismos "defensores de derechos humanos". Por otro lado, las identidades construidas no mantienen siempre el mismo signo, ni en el tiempo ni en el espacio. Volvemos con el caso de los campesinos: en casi todos los entrevistados que ostentaron una posición "campesina", se observó cierto "orgullo personal" por pertenecer a ella, no obstante, llegados a la ciudad, ese "orgullo personal” empezó a disimularse, más cuando se le aunaba, a la condición de campesino, la condición de "desplazado". Así, las identidades que se definieron "positivas" en cierta época y en cierto lugar, no necesariamente lo siguieron siendo en momentos y geografías diferentes, ni para los entrevistados, ni para sus entornos. Obsérvese bajo la misma óptica la pertenencia a un partido político como la UP (Unión Patriótica) (Entrevista No 28, 08 de julio de 2015), o a un barrio del Sector Norte de Bucaramanga (Entrevista No 19, 14 de mayo de 2014). Del mismo modo, debe entenderse que estos elementos sociales tampoco fueron absolutamente "sociales", es decir, necesitaron de ciertas mediaciones por parte de los sujetos para que pudieran objetivarse en las identidades de los mismos.

En cuanto a los elementos subjetivos, es decir, las valoraciones y percepciones salidas de la opinión personal de los entrevistados, éstos refirieron de sí mismos y de otros, cualidades como la honestidad, el liderazgo, la laboriosidad, la responsabilidad, el emprendimiento, entre otras; en un sentido peyorativo, y más refiriéndose a otros que a sí mismos, adjudicaron epítetos como "mujeriegos", "borrachos", "tercos", "machistas", "hijueputas", "corruptos", entre otros. Siguiendo con la dialéctica planteada en el anterior párrafo, estos elementos subjetivos también tienen que considerarse dentro de condiciones sociales y culturales más amplias.

Un referente de identidad que queremos tratar aparte es que el que se ha venido conformando alrededor de la palabra "víctima". Podríamos decir, con un margen de error, que esta noción se ha venido des-satanizando desde hace algunos años atrás, especialmente con la aprobación de la Ley de 1448 de 2011 (Ministerio del Interior y de Justicia, 2011). En términos formales, antes de la promulgación de esta ley no existían víctimas del conflicto en Colombia. Los desplazados eran una realidad de a puño que ni la Ley 387 de 1997 (Congreso de Colombia, 1997), ni los escuadrones policiales de las ciudades pudieron contener. La desaparición forzada, por otro lado, solo fue reconocida como delito en el año 2000 (Congreso de Colombia, 2000), después de más de 20 años de lucha por parte de los familiares de detenidos desaparecidos. Así, tal como lo expresaron las entrevistas 29 y 30, muchas víctimas del conflicto armado interno colombiano no sabían ni siquiera que eran víctimas, ni que los hechos de violencia que habían sufrido se podían denunciar. Los esfuerzos que diferentes organizaciones adelantaron en defensa de los afectados se circunscribieron dentro de los marcos jurídicos ya citados o apelando al derecho internacional.

Por otra parte, las víctimas venían adelantando esfuerzos de asociación desde orillas políticas diferentes: por un lado, las víctimas de crímenes de Estado y paramilitares, y por el otro, las víctimas de las insurgencias. Ante este panorama, fue la Ley 1448, con su noción de "victima" (artículo 3), la que empezó a configurar algo parecido a una "comunidad de víctimas", arropando bajo su protección 
a las organizaciones sociales ya descritas, a los desplazados, a los familiares de detenidos desaparecidos y a los que ni siquiera sabían que lo eran.

El proceso identitario alrededor de la Ley 1448, ha sido, sin embargo, un proceso ambiguo, pues si bien ha visibilizado, movilizado y reparado a un número importante de víctimas, también las ha despolitizado y a futuro promete fragmentarlas, no solo por haber trasladado el clientelismo a los sistemas de organización y participación de las mismas, sino también por implementar protocolos de asignación de recursos que las ponen a competir entre ellas.

En cuanto a los proyectos de vida hay dos modos de analizarlos con respecto al conflicto: primeramente, las aspiraciones que tuvieron los entrevistados antes de los hechos victimizantes, $\mathrm{y}$ segundo, las desviaciones, prescripciones o reformulaciones que tales aspiraciones experimentaron al contacto con la guerra. En cuanto a lo primero, fueron comunes entre los narradores los anhelos de familia, tierra, vivienda, estabilidad y trabajo. Estos anhelos, a su vez, fueron los más afectados por las acciones del conflicto. Por otra parte, aspiraciones más personales como estudiar, profesionalizarse o sobresalir, no fueron perjudicadas directamente por el conflicto, por lo menos no en las vidas de los entrevistados, aunque sí en sus hijos. Algunos entrevistados, ya fuera por razones familiares de antaño, por decisiones personales cuando eran jóvenes, por condiciones estructurales de la sociedad o por contingencias que le podrían haber pasado a cualquier otra persona (accidentes, enfermedades, calamidades, etc.), desistieron u olvidaron aspiraciones de este estilo. No obstante, como lo hemos dicho, fueron los hijos los mayormente afectados en la consecución de este tipo de pretensiones personales, máxime cuando la vida discurrió en un ambiente urbano, donde estudiar o profesionalizarse, por ejemplo, más que un accesorio, resultaba una necesidad u obligación en los proyectos de vida de cualquier individuo.

En cuanto al segundo modo de analizar los proyectos de vida en los entrevistados, es decir, los cambios que tales proyectos sufrieron al contacto con la guerra, hay que decir que el conflicto armado quitó esposos, hijos, hermanos, padres, primos y cuñados, afectando drásticamente los planes que a futuro anhelaban una familia estable y completa. Las mujeres que experimentaron el asesinato o la desaparición de sus esposos, por ejemplo, les fue muy difícil volver a conformar otro hogar, o por lo menos tener otra relación amorosa (Entrevista No 4, 07 de diciembre de 2013) (Entrevista 5, 21 de diciembre de 2013) (Entrevista 11, 14 de febrero de 2014) (Entrevista 14, 25 de febrero de 2014) (Entrevista 17, 30 de abril de 2014) (Entrevista 19, 14 de mayo de 2014). La gran mayoría de mujeres afectadas por estas situaciones, entrevistadas en esta investigación, han preferido mantenerse sin compañeros sentimentales. Los que quedaron sin padres, como es el caso de la entrevista 8, tuvieron que lidiar con la autoridad de sus hermanos mayores y con condiciones materiales menos óptimas. Cuando los asesinados o los desaparecidos fueron hermanos o hermanas, la sustentación de los sobrinos representó, para muchos de los entrevistados, una carga difícil de llevar (Entrevista No 28, 08 de julio de 2015) (Entrevista No 30, 23 de octubre de 2015). Una situación similar, incluso más gravosa, fue la que tuvieron que sortear algunas abuelas, cuando sus hijos fueron desaparecidos o asesinados dejando niños pequeños que ellas tuvieron que criar (Entrevista No 7, 01 de febrero de 2014). Ahora bien, no solo la desaparición o el asesinato afectó hondamente los proyectos de familia: el desplazamiento (Entrevista No 2, 02 de diciembre de 2013) (Entrevista No 20, 27 de mayo de 2014) (Entrevista No 30, 23 de octubre de 2015), las amenazas (Entrevista No 28, 08 de julio de 2015) o el 
exilio (Entrevista No 26, 31 de octubre de 2014), también perjudicaron las aspiraciones de tener familiares cercanos y unidos.

Por otra parte, cuando el conflicto liquidó tierras, viviendas y trabajo, las condiciones de muchos de los entrevistados se vieron abocadas a la desesperación. Los sueños de una casa y una economía estable tuvieron que cambiarse por la mera sobrevivencia, entonces empezaron a ser constantes los ranchos de plástico, las piezas pequeñas, las “arrimadas" en casas de parientes, la súplica por una ayuda humanitaria, la pedida de comida por las calles, etc. No obstante, muchos de los entrevistados que han vivido éstas y otras situaciones, siguen soñando y luchando por sus viviendas, por barrios más dignos, algunos se capacitan, hacen todo tipo de cursos y talleres, buscando emprender y organizarse (Entrevista No 3, 03 de diciembre de 2013) (Entrevista No 6, 23 de octubre de 2015) (Entrevista No 7, 01 de febrero de 2014). Otros, por otro lado, han perdido las motivaciones (Entrevista No 29, 13 de julio de 2015), esperan solamente morir (Entrevista No 30, 23 de octubre de 2015) o quieren irse del país (Entrevista No 2, 02 de diciembre de 2013).

Como lo hemos indicado, las identidades afirmadas o proyectadas por los individuos, tienen un contexto socioeconómico que supera las meras circunstancias del conflicto. Este contexto, que es estructuralmente violento, lo padecen paradójicamente, en mayor proporción, los mismos que sufren o han sufrido la violencia del conflicto, es decir, las poblaciones pobres. Esto, sin duda, marca unas diferencias muy considerables entre víctimas, pues no es lo mismo ser víctima con todos los recursos disponibles, que serlo con todos los recursos en contra. En la entrevista 6 y 29, por ejemplo, vemos una situación de pobreza muy remarcada en los recuerdos de la infancia de los entrevistados, así como cuadros culturales donde la violencia se concibió como un modo de resolver los conflictos cotidianos. Se entiende, entonces, por qué los grupos armados hallaron cabida en dichos territorios y por qué la paz, en la opinión enfática de los entrevistados, no puede conseguirse sin erradicarse la pobreza.

En las entrevistas 6 y 30, siguiendo con esta idea, vemos que los entrevistados señalan problemas de delincuencia común en el barrio donde residen, un barrio conformado en su mayoría por personas en situación de desplazamiento. Esta problemática les ha merecido el renombre de un "barrio peligroso" y el estigma de los sectores aledaños. Incluso, según los testimonios recolectados, cuando jóvenes de allí van a pedir empleo, son rechazados de plano por residir allí. La paradoja aquí, entonces, es que una comunidad que había sido identificada como víctima, ahora es reseñada como una comunidad de delincuentes, y con ello, una comunidad de reos, pues la intervención policial y las capturas, en estas situaciones, no se hacen esperar.

\section{Referentes de memoria}

Los referentes de memoria fueron definidos por la investigación anterior como los "tiempos, lugares, personas, sonidos y objetos" que, por el accionar de la violencia, han marcado la memoria de las víctimas de manera indeleble (Suárez Pinzón, y otros, 2013, pág. 366).

En la presente investigación encontramos que la infancia es para muchas de las personas entrevistadas un referente de memoria muy fuerte. En relación con el conflicto, las entrevistas 24 y 30, por ejemplo, dan cuenta de cuadros muy crueles en los que los entrevistados fueron testigos oculares de hechos atroces propiciados por los chulavitas durante el periodo de La Violencia, hechos como el acuchillamiento y empalamiento de niños o la quema de casas. En la entrevista 5, la narradora recuerda cómo los paramilitares impactaron la infancia de los pequeños que estudiaban en una escuela 
que ella presidía en una zona rural del nororiente del país. Según su relato, éstos hombres entraron a los salones de clase y mediante bombones y dulces les sacaron información a los niños sobre las actividades de sus padres, mientras, además, les enseñaban a manejar las armas. La madre de una de estas niñas, precisamente, fue asesinada por estos paramilitares gracias a la información que de ella dio su hijita.

Los victimarios son otros referentes de memoria reseñados en las entrevistas. Es muy común que las víctimas se acuerden de lo sucedido diciendo el nombre del victimario o su alias, incluso, que asistan a sus declaraciones de Justicia y Paz cuando son paramilitares, o que acepten sus solicitudes de perdón. Si el victimario ha sido el Ejército, los entrevistados recuerdan rangos y nombres de los responsables, así como las unidades militares a las que estaban adscritos. Tener tan presente el victimario, se concibe como un acto de justicia, de continua denuncia y resistencia; además, todos estos datos son un pedazo de verdad que las víctimas han conseguido con mucho esfuerzo, trabajo e investigación, en ocasiones poniendo en riesgo sus propias vidas (Testimonio No 26, 03 de febrero de 2016).

Los entrevistados cuando recuerdan también referencian a las víctimas directas (en el caso de los desaparecidos o asesinados): pronuncian sus nombres y apellidos completos, hacen un recuento de su vida, describen sus cualidades, repiten las frases predilectas que usaban, exponen las fotografías en las que aparecen, sus documentos de identidad, e incluso, las agendas donde escribían. Casi nunca traen a colación sus defectos. En la entrevista 19 vemos cómo la entrevistada recuerda a su esposo: en ocasiones se refiere a él como un padre de familia responsable, fanático y jugador de fútbol, pero también como un "perro", es decir, un hombre de varias mujeres. De alguna manera analizar esto es bastante complejo, pero en últimas podemos decir que la condición de "perro" es un aspecto que la entrevistada consideraba tolerable (incluso hay risa cuando lo dice). Si partimos que casi siempre se recuerda a los seres queridos desde sus virtudes, no es absurdo afirmar que, en medio de una sociedad machista y patriarcal como la colombiana, donde al hombre se le celebra tener varias mujeres, esta condición de "perro" fuera visto de manera positiva, a pesar del tono de reproche con que la entrevistada lo manifiesta. Debemos añadir también que la entrevistada recuerda que fue un hombre que se separó de su anterior pareja por no darle hijos y se puso muy contento cuando ella le dio un hijo varón.

Otros referentes evocados fueron los lugares físicos como los ríos (Entrevista 17, 30 de abril de 2014) (Entrevista No 29, 13 de julio de 2015), las veredas, los puentes, el batallón (Entrevista No 29, 13 de julio de 2015), las carreteras o caminos (Entrevista No 10, 20 de enero de 2016) (Entrevista No 24, 04 de septiembre de 2014) (Entrevista No 27, 21 de mayo de 2015), la cárcel (Entrevista No 28, 08 de julio de 2015) (Entrevista No 29, 13 de julio de 2015), las casas, las fincas, los barrios, entre otros. Los entrevistados también referenciaron objetos en el ejercicio de recordación: las armas, las listas donde sus nombres estaban inscritos, las botas de los combatientes, los uniformes, el balde de la tortura, los brazaletes, las motocicletas en que se transportaban los victimarios, la ropa con la que salieron desplazados, etc.

La pobreza, la humillación, la tortura, los bombardeos, los atentados, las llamadas telefónicas informando el asesinato o la desaparición de un familiar, los secuestros, los combates o el paso de tropas, son situaciones que los entrevistados también recuerdan continuamente y con mucho detalle. La gente también hace consciencia del paso del tiempo mediante el recuerdo del precio de las cosas: el arriendo de la pieza, los pasajes de bus o tren, los salarios o jornales, el costo de un desayuno, etc. 
Algo que poco apareció en las entrevistas, pero que es bueno ir teniendo en cuenta para las próximas investigaciones, es el uso de las actuales redes sociales por parte de las víctimas para recordar a sus familiares muertos o desaparecidos. En la entrevista 19 vemos que la hija de la entrevistada recuerda a su padre desaparecido por medio de fotos, videos y la expresión de mensajes en la red social de Facebook.

No obstante, como ya se ha dicho en un sinnúmero de ocasiones, la memoria tiene contingencias marcadas por los olvidos y los silencios, lo que Acevedo también denomina como memorias reservadas. Estos olvidos pueden ser inconscientes o conscientes, es decir, los entrevistados pueden realmente no acordarse de ciertos hechos, ya sea por la mediación del tiempo o por alguna acción involuntaria de su sistema de percepción; pero también pueden ser olvidos conscientes en la medida que los entrevistados los pretenden o los elaboran; en este artificialidad del olvido, el silencio juega un papel fundamental, no tanto en el presente como en el futuro, pues la ausencia de transmisión puede abocar a un olvido efectivo en una o dos generaciones. En la experiencia de la presente investigación, se pudo constatar que algunas personas exigían apagar las grabadoras para luego decir algo. En ocasiones estos cortes podrían estar motivados por razones de miedo o de vergüenza, sea la razón que sea, la tendencia de dichos cortes o silencios es inevitablemente el olvido.

\section{Marcos sociales de la memoria}

La investigación pasada, a la que nos hemos venido refiriendo, definió los marcos sociales de la memoria, siguiendo a Halbwachs como escenarios de interacción social mediante los cuales los individuos construyen la memoria, retomado por (Suárez Pinzón, y otros, 2013, pág. 366). En la presente investigación se pudo obtener información de por lo menos cinco (5) de estos escenarios: la familia, las religiones, los medios de comunicación, el Estado y las organizaciones sociales.

La familia fue el ámbito, quizá el primero, en que las transmisiones de información de tipo histórico influyeron de una manera sobresaliente en la percepción de los entrevistados. No obstante, más que proporcionar datos, la familia proveyó, muy ligada a la religión, un sistema de valoración para tales datos: lo correcto y lo incorrecto, lo bueno y lo malo, lo heroico y lo malvado. Sin embargo, si la familia es un marco social de la memoria, también puede ser su inverso, es decir, un marco social para el olvido. No todos los abuelos o padres se interesaron por trasmitir lo vivido durante el período de La Violencia, no solo porque recordarlo fuera duro y horroroso, sino también porque los canales de comunicación con los adultos de aquella época eran un aprieto: interrumpir conversaciones de "grandes", o atreverse a disentir, o siquiera preguntar, significaba un castigo que lo chiquilines preferían evitar. La cosa se ponía todavía más difícil si los interesados en la información eran mujeres. Los adultos, según data una parte significativa de las entrevistas, fueron representados como ásperos, gruñones, golpeadores, ausentes, estrictos o que solo les interesaba que los pequeños trabajaran; las muestras de cariño eran inexistentes y el lenguaje no era mejor. Hoy día, que la situación del afecto parece ser distinta, las familias, no obstante, siguen reproduciendo el olvido. Hay muchas referencias de hijos que les dicen a sus madres que no relaten lo que tuvieron que vivir en el conflicto (Entrevista No 30, 23 de octubre de 2015), o de hermanos que regañan a sus hermanas por dejarse entrevistar (Entrevista No 8, 29 de octubre de 2015). Al interior de algunas familias no se habla del hermano asesinado (Entrevista No 24, 04 de septiembre de 2014), o del padre desaparecido (Entrevista No 7 , 
01 de febrero de 2014), no por temor a represalias solamente, sino por mera y física salud emocional. Claro está, también están las familias unidas alrededor del dolor y la memoria (Entrevista No 28, 08 de julio de 2015), pero se puede notar una importante tendencia a "no contar", a callar, a pasar desapercibidos como víctimas.

Las religiones, en lo que se refiere a los hechos del conflicto, no aportan mayor cantidad de información. Su gran influencia con respecto a estos hechos estriba en los marcos interpretativos que les otorgan a los entrevistados que las practican. - Un análisis más profundo sobre la religión se está trabajando en un artículo aparte, aunque se pueden ver algunas aproximaciones en el libro titulado Trayectorias de resistencia y dolor, en proceso de edición -.

Los medios de comunicación por otro lado, si bien gozan de una reputación "caída" entre los entrevistados, no por ello han dejado de ser un escenario que moldea o influye la percepción de los mismos sobre el conflicto. En la entrevista 6, por ejemplo, el entrevistado argumenta su postura uribista refiriéndose constantemente a lo que ve en los noticieros televisivos. Sus opiniones sobre el proceso de paz de La Habana viraron en el mismo sentido, temiendo, por ejemplo, que una situación tan mala como la que vive Venezuela hoy, según él, pudiera trasladarse a Colombia con el ascenso político de las guerrillas. Los medios de comunicación también han tenido su cuota en la visión humanitarista y "amarillista" de los hechos acaecidos durante el conflicto: la fijación en algunos hechos sin ningún contexto de por medio, la exacerbación y la omisión de otros, son prácticas mediáticas que influyen considerablemente en las opiniones de los entrevistados; y aunque no faltan, entre éstos, las posiciones críticas y argumentadas contra dichas fuerzas de la comunicación, es una realidad que una gran cantidad de víctimas poseen niveles de lectura muy bajos, poco acceso a internet, algunas se conservan analfabetas y otras no culminaron la primaria o el bachillerato.

El Estado, por otra parte, ha tenido en los últimos años una incidencia portentosa en la configuración de la memoria del conflicto, no solo entre los entrevistados, sino en toda la sociedad colombiana. La creación del Centro Nacional de Memoria Histórica (CNMH) y de sus respectivas Direcciones ha contribuido a tal fin. Si bien con esta postura estatal las víctimas han hallado una mayor visibilización y las organizaciones sociales y académicas la impronta de algunos recursos para la ejecución de proyectos de investigación sobre memoria, no ha sido posible una autonomía auténtica de éstos con respecto a la línea oficial. Por un lado, es la institucionalidad la que dispone de los recursos; por el otro, esta misma institucionalidad es la que tiene el mejor sistema de elaboración de relatos sobre el conflicto en el país: no solo cuenta con personal destacadísimo y abundante, sino también con la infraestructura adecuada para su funcionamiento (sedes físicas, plataformas virtuales, articulación interinstitucional, etc.) y, lo más importante, con un discurso acaparador. La postura de las memorias plurales, principal eje de este discurso, donde todos caben, víctimas y victimarios, donde el fin es la reconciliación, donde los aspectos estructurales no se tocan, donde todo es cuestión de buenas voluntades, es un discurso "bello", que lastimosamente ha permeado a las víctimas y sus organizaciones, pero es un discurso ineficiente en la resolución de las problemáticas concretas de la victimización y el conflicto. Una política de memoria sin reformas socioeconómicas es solo un accesorio de ilusión democrática y un discurso legitimador para que las condiciones estructurales que suscitan el conflicto se mantengan intactas. 
Las organizaciones sociales, último marco que queremos abordar, se mueven en distintas medidas con respecto a esta crítica. Ellas han aportado de manera considerable a las construcciones de memoria que sobre el conflicto han aprehendido las víctimas, no obstante, su impacto es muy desigual con respecto a las iniciativas mediáticas o gubernamentales. Esta desigualdad se debe en primer lugar a que han tenido que mantenerse a la defensiva, la represión con la que han tenido que lidiar las ha replegado a la sobrevivencia, y les ha restado fuerza en su tarea de constituirse una alternativa. Otro aspecto que ha operado en su detrimento ha sido la sustentabilidad. Cada día son más escasos los recursos internacionales y las organizaciones, para mantenerse, han tenido que adherirse a los protocolos gubernamentales o desaparecer (caso de la Fundación para la promoción de la Cultura y la Educación Popular-FUNPROCEP-). Esto, como lo hemos señalado, no permite autonomía. Por otro lado, se observa en las distintas mesas de participación de víctimas, o en los espacios de confederación de las organizaciones sociales, ciertos problemas de articulación o de divisiones internas. Ahora bien, a pesar de todas estas problemáticas, el rol de las organizaciones sociales sigue siendo fundamental en la movilización de las víctimas por la memoria, su permanencia en el ambiente público, les ha servido para mantener una interlocución continua con los demás agentes sociales, académicos e institucionales.

\section{Expresiones de memoria}

Las expresiones de memoria las hemos definido como aquellas fórmulas de exposición que las víctimas encuentran para manifestar o dar cuenta de su experiencia con relación al conflicto. Son, digámoslo así, apuestas más articuladas y complejas, que pueden contener en sí varios elementos relacionados con los referentes o marcos sociales de memoria, así como contextos e interpretaciones personales. En la entrevista 2, por ejemplo, el entrevistado ha usado su talento musical para expresar, mediante letras y ritmos vallenatos, las vivencias de las torturas, amenazas y desplazamientos de los que él fue víctima. En esas canciones no solo se plasma el dolor, sino también las lecciones y los agradecimientos para con Dios, quien, según él, fue el ser que más lo ayudó en todas sus penumbras.

La persona de la entrevista 26, en un intento similar, ha escrito poemas, no solo relacionados con sus hechos personales, sino también con los acaecidos a compañeros de su juventud, hoy por hoy detenidos desaparecidos o asesinados.

En la entrevista 29, por otro lado, la memoria sobre la época de La Violencia llegó al entrevistado en forma de leyenda: un mendigo que de repente se convertía en justiciero y asesinaba a los finqueros que violaban las esposas de los campesinos, o que robaban la pesca o que abusaban de sus trabajadores. Él cuenta que lo vio, pero la mayor parte de la leyenda le fue transmitida por su madre.

Las víctimas de desaparición forzada exponen continuamente sus memorias mediante galerías, hacen liturgias en honor de sus desaparecidos, prenden velas, sueltan globos, cantan canciones u ofrecen flores. Son igualmente activos en fechas conmemorativas como la Semana del Detenido Desaparecido o el Día de la Desaparición Forzada y cuando aparecen los restos de alguien lo asumen como si fuera el familiar de todos. Por otra parte, todas las víctimas organizadas participan del 9 de abril, ya sea marchando, haciendo eventos culturales, plantones o foros académicos. 
Por último, los entrevistados han expresado su memoria hablando, dando una entrevista, ofreciendo un relato y, para el caso de esta investigación, dándolo en conservación a un archivo. Otros, además de hablar, han intentado por sí mismos escribir y hacer sus propios archivos.

\section{Conclusiones}

La relación del conflicto armado interno colombiano y el Área Metropolitana de Bucaramanga, dentro de los estudios históricos de esta ciudad, es todavía una tarea pendiente. El fenómeno que más se ha asimilado en la actualidad, con respecto a esta relación, es el que tiene que ver con el rol de “receptora de víctimas” (Lamus \& Useche, 2002, pág. 28; Castro Lee, 2005, pág. 394; Suárez, y otros, 2013, pág. 24) que ha desempeñado esta zona en las tres últimas décadas. La investigación que ha producido el presente artículo si bien no escapa a este marco, ha encontrado elementos para ampliarlo.

Los elementos aquí destacados bien pueden entenderse como una aproximación de cómo las víctimas asentadas en el Área Metropolitana de Bucaramanga hacen memoria del conflicto en la actualidad. Dentro de esta aproximación no hay duda que debe haber diferencias con otras zonas del país, pero, por lo general, consideramos que son mucho más los asuntos en común. Documentar estos asuntos para esta parte de Colombia, en la que por falta de investigaciones da la impresión de ser una zona tranquila y sin mayores traumatismos a razón del conflicto, es en sí un logro valiosísimo, toda vez que contribuye, con asidero científico, a un análisis más amplio y globalizante de este medio siglo de guerra interna.

Más que datos novedosos, hemos querido resaltar algo que tampoco es novedad, pero sí muy escaso, a saber, la necesidad de profundizar en los enfoques críticos de la memoria.

A modo de síntesis, queremos indicar algunos aspectos encontrados en la investigación que pueden aportar en este sentido: en primer lugar, el análisis dialéctico. Los estudios de memoria requieren considerar, de manera seria y rigurosa, los clásicos planteamientos entre objetividad y subjetividad, conciencia y clases sociales, cuestión nacional e imperialismo, Estado y economía, entre otros, con el fin de ubicar más correctamente, dentro de la realidad social, los análisis hechos a la información recolectada y las acciones que se pueden desprender de dichos análisis.

Un segundo elemento, que ya hemos insinuado en otros apartados de este escrito y útil para afirmar un carácter crítico de los estudios de memoria, es la necesaria aplicación de una perspectiva histórica. Esta perspectiva va más allá de la mera contextualización que se hace a un testimonio o entrevista, tiene que ver con la comprensión de dicho contexto por parte de entrevistados e investigadores; los primeros con el fin de entender sus trayectorias de vida en el marco de unas estructuras que le han determinado de forma casi inconsciente, y los segundos, para complementar y/o criticar la historia académicamente conocida y dejarse "afectar" (o “tocar") por lo que están aprehendiendo. La perspectiva histórica en función de la comprensión representa la posibilidad de una conciencia histórica, es decir, el entendimiento del presente a partir de la conexión con el pasado, propiciando explicaciones de carácter racional y no las típicas causalidades relacionadas con la religión, la suerte o la resignación del desconocimiento ("no sê"). Para el caso de la presente investigación, se ha intentado advertir la perspectiva histórica en la ligazón real que existe entre el período de La Violencia y el actual conflicto, las iniciativas paramilitarizadas del Estado colombiano desde los inicios de la segunda mitad del siglo XX, el anticomunismo propiciado por las potencias imperialistas desde la segunda década del 
mismo siglo, la Doctrina de Seguridad Nacional dentro de este anticomunismo y/o las condiciones que hicieron surgir las insurgencias.

Un tercer y último elemento, es la valoración crítica de los propósitos que se tienen a la hora de hacer memoria, ya sea desde el Estado, ONGs, víctimas, academia, sectores económicos, corporaciones internacionales, iglesias o medios de comunicación. Esta valoración debe ponderar los aspectos positivos, las limitantes y las equivocaciones de tales propósitos, los alcances de sus métodos, marcos teóricos e impactos. Tal posición es claramente opuesta a la neutralidad, pero no a la objetividad, pues de lo que se trata es ser lo más científicamente rigurosos en el conocimiento de lo social, pero también políticamente activos en pro de reivindicaciones justas. Desde AMOVI-UIS tal pretensión es lo que hemos denominado memoria histórica rąonada.

Somos conscientes que esta propuesta es muy ambiciosa, no obstante, seguimos considerando que es la ruta por la que se debe transitar si queremos aportar a las transformaciones sociales que se requieren. Es necesario admitir que, en la presente investigación, solo se pudo hacer memoria histórica razonada hasta cierto punto: por un lado, las condiciones actuales del país, de un Estado paramilitarizado y no garante de los derechos fundamentales, hacen demasiado restringidas y arriesgadas las discusiones sobre el conflicto armado interno, no solo en el ámbito público (especialmente en las regiones), sino también en espacios comunales o colectivos. Por otro lado, la medición de los objetivos de la memoria histórica razonada requiere de tiempo, por lo tanto, se necesitan procesos continuos e institucionalizados que aseguren una perdurabilidad que sobrepase el carácter esporádico que hasta ahora han tenido los proyectos que han propuesto esta alternativa. Además, debe tenerse en cuenta que hacer memoria histórica razonada también está determinado por las condiciones subjetivas de investigadores y entrevistados, en otras palabras, es muy difícil conocer hasta dónde son factibles el compromiso y la voluntad de estos sujetos en pro de la consecución de trabajos memoria de este tipo.

La acción de narrar, y de narrar no solo los hechos victimizantes sino toda su vida hasta el presente, es quizá de los logros más importantes que tenga la presente investigación en cuanto memoria histórica razonada se refiere, pues dicha acción les da a las víctimas otros puntos de partida y de llegada para evaluar sus experiencias dentro del conflicto. Más allá de eso, es muy difícil garantizar que el conflicto se vaya comprender en sus dimensiones sociopolíticas y que tal comprensión vaya a suscitar la movilización social generalizada. Como lo hemos dicho, se requiere de un ambiente y unos sujetos sociales que alienten estos fines. No obstante, hemos empezado, esperamos que el material hasta ahora elaborado y las ideas expuestas fecunden en "buena tierra".

Para terminar, si bien en los últimos treinta años Bucaramanga y sus alrededores han surtido el papel de "receptores" de víctimas, la investigación ha puesto en evidencia que dicho papel no anula la vinculación de esta ciudad con procesos de victimización que, ocurridos a su interior, se encuentran en el marco del conflicto armado que vive el país, no solo durante estos últimos treinta años, sino incluso desde mucho antes. Los testimonios y las entrevistas recolectadas, la interrelación con organizaciones sociales, las conversaciones con líderes locales de la "vieja guardia", los diálogos con otros investigadores y pesquisas en prensa o material bibliográfico, nos han sugerido que la relación del conflicto colombiano con la sociedad bumanguesa y sus contornos va más allá de la mera "recepción de víctimas" y sufre, además, de una peligrosa amnesia. 
En el imaginario colectivo de los habitantes de esta zona (especialmente entre los más jóvenes) se puede percibir un claro proceso de des-memoria que ha constreñido casi al olvido los desaparecidos y asesinados de la Universidad Industrial de Santander (UIS), la represión al movimiento cultural contestatario de los años de 1980 (el proyecto de tesis titulado Una brecha de fuego: el caso del grupo cultural El Sembrador y el poeta Chucho Peña en la ciudad de Bucaramanga, 1977-1986, del candidato a magister Jorge Garavito, empieza a mostrar luces con respecto a esta temática -ver referencia-)., las llamadas "limpiezas sociales" o el asesinato de importantes líderes locales como Carlos Toledo Plata. Estos hechos, entre muchos otros, entrañablemente conectados con las dinámicas del conflicto colombiano dentro del ámbito local, ni la historiografía, ni los movimientos sociales, han logrado posicionarlos en la conciencia de los ciudadanos bumangueses, advirtiendo, con ello, el saldo negativo que tiene esta región con su memoria histórica.

La historiografía sobre esta temática es poca. Los trabajos más relevantes que se pueden relacionar con este tipo de hechos son los de Jhoney Díaz Fajardo y Álvaro Acevedo Tarazona. El primero ha trabajado las luchas cívicas en Santander entre 1970-1984, destacando para Bucaramanga las protestas estudiantiles, los paros cívicos y el asesinato de Carlos Toledo Plata (Díaz Fajardo, 2013, págs. 175183). Acevedo Tarazona, por otro lado, se ha especializado la conflictividad al interior de la UIS (Acevedo Tarazona, 2004; Acevedo Tarazona \& González Rey, 2011).

\section{Referencias Bibliográficas}

Acevedo Arango, O. F. (2012). Geografías de la memoria: posiciones de las víctimas en Colombia en el período de justicia transicional (2005-2010). Bogotá: Pontificia Universidad Javeriana.

Acevedo Tarazona, A. (2004). Modernización, conflicto y violencia en la universidad en Colombia: AUDESA (19531984). Bucaramanga: Universidad Industrial de Santander.

Acevedo Tarazona, A., \& González Rey, D. C. (julio-diciembre de 2011). Protesta y movilización estudiantil, 1964. Memoria de una marcha en laUniversidad Industrial de Santander. Anuario Colombiano de Historia Socialy de la Cultura, 38(2), 255-276.

AMOVI. (2010). Archivo oral de memoria de las Victimas - Fase 1. Bucaramanga: Amovi. Obtenido de http://www.uis.edu.co/webUIS/es/amoviUIS/index.html

Castro Lee, C. (. (2005). En torno a la violencia en Colombia. Una propuesta interdisciplinaria. Cali: Universidad del Valle.

Congreso de Colombia. (1997). Ley 387 de 1997. Recuperado el 13 de marzo de 2017, de https://www.unidadvictimas.gov.co/sites/default/files/documentosbiblioteca/ley-387-de-1997.pdf

Congreso de Colombia. (2000). Ley 589 de 2000. Recuperado el 13 de marzo de 2017, de http://www.alcaldiabogota.gov.co/sisjur/normas/Norma1.jsp?i=14507

Díaz Fajardo, J. (2013). Ciudad y protesta: Las luchas cívicas enSantander 1970-1984. Anuario de Historia Regional y de las Fronteras, 18(1), 161-191.

Escamilla Márquez, D. A. (2013). Puesta en marcha de un archivo oral de memoria en el Área Metropolitana de Bucaramanga. Verdades no contadas: el conflicto armado interno colombiano desde la memoria de lasvíctimas. Bucaramanga: Universidad Industrial de Santander.

Escamilla Márquez, D. A., \& Novoa Sanmiguel, L. (2016). Archivos orales y memoria delconflicto armado interno colombiano: retos y posibilidades. ADVOCATUS, 14(27), 153-173. 
Escamilla Márquez, D. A., \& Novoa Sanmiguel, L. (2017). Conflicto y memoria: trayectorias de vida como metodología para comprender el conflicto armado colombiano. Revista Colombiana de Ciencias Sociales, 8(1), 65-87.

Garavito Cárdenas, J. A. (pendiente de publicación). Una brecha de fuego: el caso del grupo cultural El Sembradory el poeta Chucho Peña en la ciudad de Bucaramanga, 1977-1986. Proyecto de tesis para optar al título Magister en Historia de la Universidad Nacional de Colombia, Bogotá.

Gentile, B. (2015). El recuerdo del "mal”: Historizar la memoria. El Ágora USB, 15(1), 365-374. doi:http://dx.doi.org/10.21500/16578031.1619

Lamus, D., \& Useche, X. (2002). Maternidad y paternidad: tradición y cambio en Bucaramanga. Bucaramanga: Universidad Autónoma de Bucaramanga.

Ministerio del Interior y de Justicia. (2011). Ley de víctimas y restitución de tierras. Bogotá: Imprenta Nacional.

Murgia, E. I. (septiembre de 2011). Archivo, memoria e historia: cruzamientos y abordajes. Íconos. Revista de Ciencias Sociales(41), 17-37.

Ricoeur, P. (2000). La memoria, la historia, el olvido. Buenos Aires: Fondo de Cultura Económica.

Suárez Pinzón, I., Ardila , E., Baéz, J. S., \& Rueda, J. F. (2010). Estudio de trayectorias de vida de personas en situación de desplazamiento forzado interrelacionadas en el barrio Café Madrid del municipio de Bucaramanga. Proyecto Colciencias, ejecutado por la UIS y asesorado por la Corporación COMPROMISO, Bucaramanga.

Suárez Pinzón, I., Martínez, E., Novoa Sanmiguel , L., Ardila , E., Rueda, J. F., \& Oyola, A. (2013). Trayectorias de vida de veinticinco víctimas del desplazamiento forzado asentadas en el barrio Café Madrid de Bucaramanga. Bucaramanga: Colciencias, UIS, COMPROMISO.

Villa Gómez, J. D. (2013). Memoria histórica desde las Victimas del conflicto armado Construcción y reconstrucción del sujeto político. Kavilando, 5(1), 11-23. Obtenido de http://kavilando.org/revista/index.php/kavilando/article/view/96/82

\section{Notas:}

i Artículo derivado de la investigación Puesta en marcha de un archivo oral de memoria en el Área Metropolitana de Bucaramanga. Verdades no contadas: el conflicto armado colombiano desde la memoria de las víctimas. Fase 2, aprobada y financiada por la Vicerrectoría de Investigación y Extensión de la Universidad Industrial de Santander (UIS), entre los años 2016-2017. 